\title{
Reduced graphene oxide and inorganic nanoparticles composites - synthesis and characterization
}

\author{
Magdalena Onyszko ${ }^{1}$, Karolina Urbas ${ }^{1 *}$, Malgorzata Aleksandrzak ${ }^{1}$, Ewa Mijowska ${ }^{1}$ \\ ${ }^{1}$ West Pomeranian University of Technology, Szczecin, Institute of Chemical and Environment Engineering, Piastów 45, \\ 70-311 Szczecin, Poland \\ "Corresponding author: e-mail: kurbas@zut.edu.pl
}

\begin{abstract}
Graphene - novel 2D material, which possesses variety of fascinating properties, can be considered as a convenient support material for the nanoparticles. In this work various methods of synthesis of reduced graphene oxide with metal or metal oxide nanoparticles will be presented. The hydrothermal approach for deposition of platinum, palladium and zirconium dioxide nanoparticles in ethylene glycol/water solution was applied. Here, platinum/ reduced graphene oxide $(\mathrm{Pt} / \mathrm{RGO})$, palladium/reduced graphene oxide $(\mathrm{Pd} / \mathrm{RGO})$ and zirconium dioxide/reduced graphene oxide $\left(\mathrm{ZrO}_{2} / \mathrm{RGO}\right)$ nanocomposites were prepared. Additionally, manganese dioxide/reduced graphene oxide nanocomposite $\left(\mathrm{MnO}_{2} / \mathrm{RGO}\right)$ was synthesized in an oleic-water interface. The obtained nanocomposites were investigated by transmission electron microscopy (TEM), X-ray diffraction analysis (XRD), Raman spectroscopy and thermogravimetric analysis (TGA). The results shows that GO can be successfully used as a template for direct synthesis of metal or metal oxide nanoparticles on its surface with a homogenous distribution.
\end{abstract}

Keywords: reduced graphene oxide, platinum nanoparticles, palladium nanoparticles, zirconia nanoparticles, manganese dioxide nanoparticles.

\section{INTRODUCTION}

In recent years, graphene, one of the most fascinating materials in materials science, has been widely investigated owing to its unique electronic, thermal, mechanical, and chemical properties and potential technical applications $^{\mathbf{1 - 3}}$. One of the graphene derivatives, graphene oxide, has been considered as a promising material for various applications due to its surface functionalizability, amphiphilicity, and excellent aqueous processability. These unique properties are associated with its chemical structure composed of $\mathrm{sp}^{3}$ carbon domains surrounding $\mathrm{sp}^{2}$ carbon domain and a variety of functional groups: epoxy, hydroxyl, and carboxyl groups ${ }^{4,5}$. Such structure of graphene oxide and large specific surface area make it a new 2D support to load metal nanoparticles (NPs) for various applications. Recently, a lot of efforts have been put into the harnessing the useful properties of graphene materials in composites via the incorporation with functional materials such as organic ${ }^{6,7}$ and inorganic ${ }^{8-10}$ structures, metal - organic frameworks ${ }^{11}$, biomaterials such as enzymes, molecular beacons ${ }^{12,}{ }^{13}$, carbon nanotubes ${ }^{14}$, polymers ${ }^{15,16}$, etc. Graphene-based nanocomposites are widely investigated in applications such as biomedicine ${ }^{17}$, photocatalysis ${ }^{18}$, biosensors ${ }^{13}$, batteries $^{19}$, supercapacitors ${ }^{20}$, fuel cells ${ }^{21}$, Raman enhancement ${ }^{22}$.

In the last years, a lot of attention has been paid to elaborate the methodology of obtaining graphene and graphene derivatives composites with inorganic nanostructures with controlled shape, size, crystallinity and functionality. Numerous metals, chalcogenides and metal oxides have been deposited on graphene platform, e.g. $\mathrm{Au}^{8,23,24}, \mathrm{Ag}^{24,25}, \mathrm{Pd}^{24,26,27}, \mathrm{Pt}^{24,28,29}, \mathrm{Cu}^{30}, \mathrm{Ni}^{31}$, $\mathrm{TiO}_{2}{ }^{32,}{ }^{33}, \mathrm{ZnO}^{34}, \mathrm{SnO}_{2}{ }^{35}, \mathrm{MnO}_{2}{ }^{36}, \mathrm{Fe}_{3} \mathrm{O}_{4}{ }^{37}, 38, \mathrm{SiO}_{2}{ }^{39}$, $\mathrm{CdS}^{40}$ and $\mathrm{CdSe}^{41}$.

Herein, we report a facile methods of obtaining graphene - based nanocomposites with well -dispersed inorganic nanoparticles such as palladium, platinum, zirconia and manganium dioxide of various sizes and shapes.

\section{MATERIALS AND METHODS}

\section{Synthesis of graphene oxide}

Graphene oxide (GO) was synthesised from synthetic graphite using modified Hummers method. Briefly, $135 \mathrm{ml}$ of a mixture of concentrated sulphuric acid and orthophosphoric acid (v:v = 8:1) was poured to graphite $(1 \mathrm{~g})$ and potassium permanganate $(6 \mathrm{~g})$, and stirred with magnetic stirrer for 24 hours at $50^{\circ} \mathrm{C}$. After the reaction, the mixture was poured into an ice $(150 \mathrm{ml})$ and $\mathrm{H}_{2} \mathrm{O}_{2}$ $(30 \%, 1 \mathrm{ml})$ and then centrifuged followed by washing with water, hydrochloric acid (30\%) and ethanol. Finally, the $\mathrm{GO}$ was dried in air at $60^{\circ} \mathrm{C}$.

\section{Synthesis of Pt/RGO nanocomposite}

$75 \mathrm{mg}$ of GO powder was dispersed in $150 \mathrm{ml}$ of aqueous solution of ethylene glycol (EG) (water to EG volume ratio 2:1) and sonicated for 2 hours in ultrasonic bath to obtain a homogeneous suspension. $200 \mathrm{mg}$ of $\mathrm{H}_{2} \mathrm{PtCl}_{6}$ crystals were also dissolved in an aqueous solution of ethylene glycol $\left(\mathrm{H}_{2} \mathrm{O}\right.$ to EG volume ratio $2: 1)$. The solution and suspension were mixed together followed by 1 hour sonication. After that the mixture was placed in an autoclave and vigorously stirred at $110^{\circ} \mathrm{C}$ for 24 hours. The final product of $\mathrm{Pt} / \mathrm{RGO}$ was repeatedly washed with water and ethanol, filtrated and dried in air at $60^{\circ} \mathrm{C}$.

\section{Synthesis of $\mathrm{MnO}_{2} / \mathrm{RGO}$ nanocomposite}

$\mathrm{MnO}_{2} /$ reduced graphene oxide nanocomposite $\left(\mathrm{MnO}_{2} /\right.$ RGO) was synthesised in an oleic-water interface. RGO was obtained in a thermal reduction of graphene oxide at $300^{\circ} \mathrm{C}$ under acetylene $(600 \mathrm{sccm})$ and argon $(600 \mathrm{sccm})$ atmosphere for 30 minutes. The obtained material was used as a platform for a growth of manganese dioxide nanoparticles. Briefly, $200 \mathrm{ml}$ of graphene oxide water suspension $(0.5 \mathrm{mg} / \mathrm{ml})$ was prepared by the ultrasonication process. Next, $4 \mathrm{ml}$ of oleic acid was introduced followed by pouring $4 \mathrm{ml}$ of $\mathrm{KMnO}_{4} /$ water solution 
$(100 \mathrm{mg} / \mathrm{ml})$ and stirring for $24 \mathrm{~h}$ at room temperature. The resulting material was collected by the centrifugation and washed several times with water and ethanol to remove any possible residual reactants. Finally, the product was dried in air at $100^{\circ} \mathrm{C}$ for $24 \mathrm{~h}$.

\section{Synthesis of Pd/RGO}

Graphene oxide was mixed with aqueous solution of ethylene glycol and sonicated. The same procedure was used for palladium acetate $(\mathrm{PdAc})$. Then the solutions of graphene oxide and palladium acetate were mixed together and refluxed at $110^{\circ} \mathrm{C}$ for $6 \mathrm{~h}$. Weight ratio of EG:GO was 1500:1 and GO:PdAc - 1:1. After 6 h the mixture was cooled down, filtered and washed several times with water and ethanol. The product was dried at $100^{\circ} \mathrm{C}$. In a typical procedure $75 \mathrm{mg}$ of $\mathrm{GO}, 75 \mathrm{mg}$ PdAc, $200 \mathrm{ml} \mathrm{H}_{2} \mathrm{O}$ and $100 \mathrm{ml} \mathrm{EG}$ were used.

\section{Synthesis of $\mathrm{ZrO}_{2} / \mathrm{RGO}$}

Graphene oxide was mixed with aqueous solution of ethylene glycol and placed in an ultrasonic bath. The same procedure was used for zirconium (IV) acetylacetonate ( $\mathrm{ZrAc})$. The solutions of graphene oxide and zirconium (IV) acetylacetonate in EG were mixed together. The solution of $\mathrm{HCl}$ was dropped into the mixture in order to change $\mathrm{pH}$ to 3 . The mixture was then placed in an autoclave and heated at $270^{\circ} \mathrm{C}$ for $6 \mathrm{~h}$. Then the mixture was cooled down to room temperature, filtered and washed thoroughly with water and ethanol. The product was placed in a dryer for $24 \mathrm{~h}$ at $100^{\circ} \mathrm{C}$. Weight ratio of EG to GO was 1500:1, while graphene oxide to precursor of zirconia - 1:2. In a typical procedure $75 \mathrm{mg}$ of $\mathrm{GO}$, $150 \mathrm{mg} \mathrm{ZrAc}, 200 \mathrm{ml} \mathrm{H} \mathrm{H}_{2} \mathrm{O}$ and $100 \mathrm{ml} \mathrm{EG}$ were used.

\section{Characterization}

A morphology of the samples was examined with transmission electron microscopy (TEM, Tecnai G2 F20 S-TWIN, FEI). Powder X-ray diffraction (XRD) patterns of as-prepared samples were recorded on a X'Pert Philips Diffractometer. Thermogravimetric analysis (TGA), used to verify the loading of the nanoparticles, was carried out on a TA Instrument SDT Q600 under an air flow of $100 \mathrm{~mL} / \mathrm{min}$ at heating rate of $10^{\circ} \mathrm{C} / \mathrm{min}$ from room temperature to $800^{\circ} \mathrm{C}$. Raman spectra were acquired on the inVia Raman Microscope (Renishaw) at an excitation wavelength of $785 \mathrm{~nm}$.

\section{RESULTS}

\section{Characterization of graphene oxide}

It has been established that oxidation of graphite has an effect on exfoliation of graphene layers as a result of the formation of oxygen-containing functional groups such as hydroxyl and epoxy groups that are formed on a basal plane of graphene layers and carboxyl and carbonyl groups created on graphene edges ${ }^{42}$. The efficiency of the chemical exfoliation can be analyzed with atomic force microscope which measures a thickness of graphene sheets. The topography and the height profiles of graphene oxide measured with AFM are presented on Figure 1(a) and (b), respectively. The thickness of GO sheets was established to be in the range of 0.8-1.1 $\mathrm{nm}$, which corresponds to a single-layer graphene oxide.
The enhanced thickness of graphene oxide compared to the theoretical value can be ascribed to the individual graphene sheets bearing oxygen-containing functional groups on both faces ${ }^{\mathbf{4 3}, 44}$. Further study on a morphology of graphene oxide was performed using transmission electron microscopy. TEM image of GO is presented in Figure 1(c). One can see that GO shows lamellar layered structure and slight wrinkles. The sizes of GO sheets was estimated to be in the range of $0.6-2 \mu \mathrm{m}$.

Another useful technique to analyse graphite exfoliation into graphene oxide is X-ray diffraction (Fig. 1(d)). Basing on Braggs equation, interlayer distance as an indicator of intercalation of oxygen-functional groups can be estimated. XRD pattern of GO demonstrates a sharp (001) peak at two theta of $10.842^{\circ}$ which is shifted to the lower angle in comparison to the starting graphite $\left(26.475^{\circ}\right)$, proving an increase in d-spacing from $0.334 \mathrm{~nm}$ to $0.815 \mathrm{~nm}$. This is a result of the intercalation of oxygen-functional groups and water molecules into carbon layer structure during the oxidation process ${ }^{\mathbf{4 5}, 46}$.

Figure 1(e) presents Raman spectrum of GO. Three characteristic peaks appear around $1310 \mathrm{~cm}^{-1}, 1598 \mathrm{~cm}^{-1}$ and $2591 \mathrm{~cm}^{-1}$, attributed to D, G and 2D bands, respectively. The $\mathrm{G}$ band indicates the in-plane vibrations of $\mathrm{sp}^{2}$ bonded carbon atoms and it is blue shifted compared to the pristine graphite ${ }^{47}$, due to the presence of the isolated double bonds which resonate at higher frequen$\operatorname{cies}^{48}$. The $\mathrm{D}$ band is a breathing mode of $\mathrm{A}_{1 \mathrm{~g}}$ vibrations of six-membered $\mathrm{sp}^{2}$ carbon rings, which are absent in defect-free graphene. So, D peak indicates the defect in graphene and the ratio of peak intensities $\mathrm{I}_{\mathrm{D}} / \mathrm{I}_{\mathrm{G}}$ can be used to characterize the level of disorder in graphene. Hence, the $\mathrm{I}_{\mathrm{D}} / \mathrm{I}_{\mathrm{G}}$ was calculated to be 1.45 , which fully confirms graphite oxidation. 2D band arises from a two phonon double resonance Raman process and, according to its shape and position, it is usually used to identify a number of graphene layers. The inset of Figure 1(e) presents $2 \mathrm{D}$ band of $\mathrm{GO}$ fitted with Lorentzian function. It is observed that the band is composed of 2 sub-peaks, $2 \mathrm{D}_{1}$ and $2 \mathrm{D}_{2}$, located at $2556 \mathrm{~cm}^{-1}$ and $2620 \mathrm{~cm}^{-1}$, respectively. This observation suggests that the analyzed graphene oxide is composed of two layers ${ }^{49}$.

In further study thermogravimetric analysis was used to explore the thermal stability of graphene oxide and to determine the content of oxygen-functional groups. The TGA curve presents $48 \%$ - mass loss at the temperature range of $150-300^{\circ} \mathrm{C}$, attributed to a loss of covalently bonded oxygen from the GO sheets ${ }^{50}$. The second stage of the mass loss corresponds to the bulk pyrolysis of carbon skeleton and starts at the temperature of $420^{\circ} \mathrm{C}^{\mathbf{5 1}}$.

\section{Characterization of Pt/RGO nanocomposite}

Representative TEM images of Pt/RGO nanocomposite are presented in Figure 2(a) and (b). Figure 2(a) shows typical 2D wrinkled and crumpled structure of the reduced graphene oxide sheets with uniformly distributed platinum nanoparticles on the basal planes and edges. The surface is densely packed with metal nanoparticles and no individual RGO sheets are observed. Figure 2(b) with a scale of $5 \mathrm{~nm}$ reveals the crystalline features of platinum nanoparticles with the spherical shapes.

XRD pattern of Pt/RGO composite, presented in Figure $2(\mathrm{c})$, shows the diffraction peaks at $2 \theta$ of $39.7^{\circ}, 46.3^{\circ}$, 


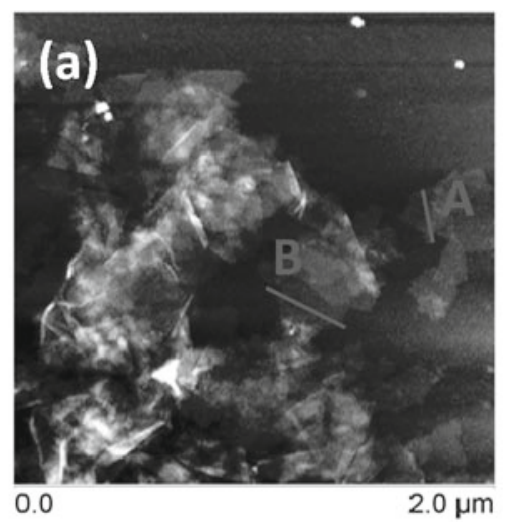

(c)

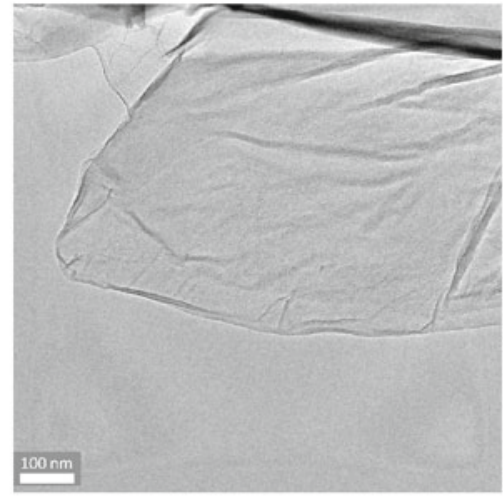

(e)

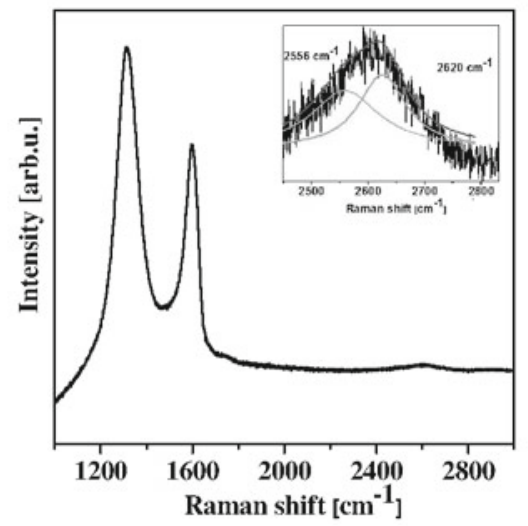

(b)
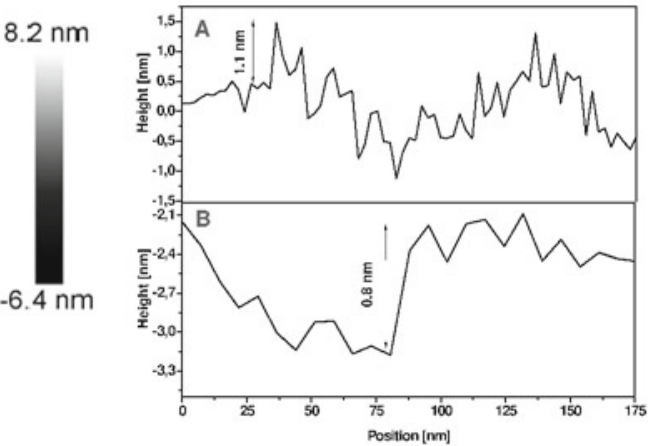

(d)

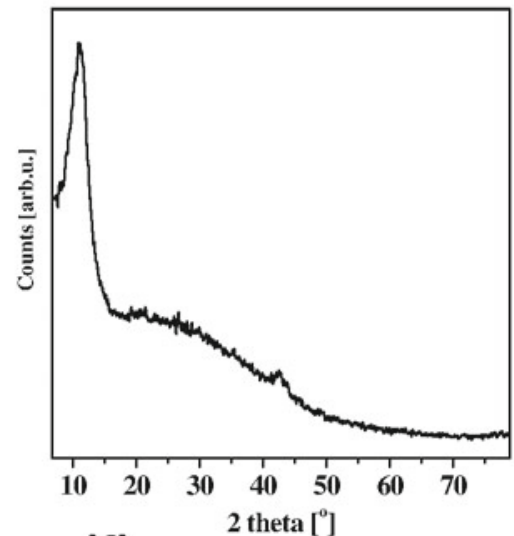

(f)

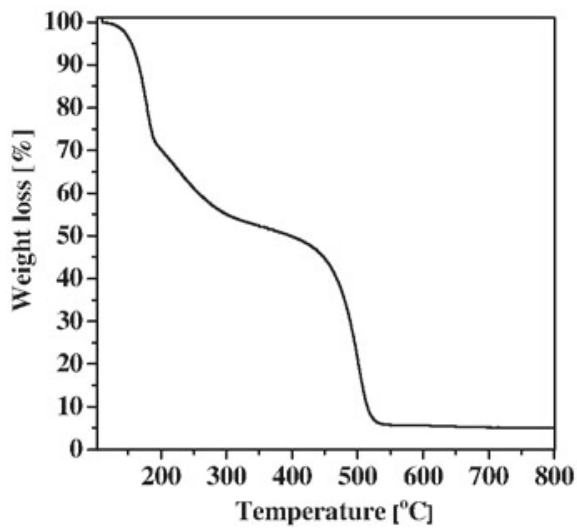

Figure 1. (a) AFM image, (b) height profile, (c) TEM image, (d) XRD pattern, (e) Raman spectrum and (f) TGA curve of graphene oxide

$67.6^{\circ}$, and $81.5^{\circ}$, which can be assigned to (111), (200), (220), and (311) reflections of Pt with face-centered-cubic (fcc) phase, respectively ${ }^{\mathbf{5 2}, \mathbf{5 3}}$.

Figure 2(d) presents Raman spectrum of Pt/RGO nanocomposite. The spectrum exhibits two bands, D and $\mathrm{G}$ bands, which appear at 1314 and $1596 \mathrm{~cm}^{-1}$, respectively. The ratio of $D$ and $G$ peaks intensities $\left(\mathrm{I}_{\mathrm{D}} / \mathrm{I}_{\mathrm{G}}\right)$ was used to characterize the level of disorder in graphene. For pristine graphene oxide $\mathrm{I}_{\mathrm{D}} / \mathrm{I}_{\mathrm{G}}$ equals 1.45 and for $\mathrm{Pt} / \mathrm{RGO}$ nanocomposite -1.43 . There is no significant difference between these values what can be the effect of the release of functional groups during the reduction process and simultaneous replacement of the vacancies by platinum nanoparticles.
Figure 2(e) shows the thermal behavior of Pt/RGO. The TGA curve shows about $3 \mathrm{wt} \%$ loss at the temperature range of $25-150^{\circ} \mathrm{C}$ which is due to the loss of water. About $3 \mathrm{wt} \%$ loss up to $250^{\circ} \mathrm{C}$ and $28 \mathrm{wt} \%$ loss in the range of $280-450^{\circ} \mathrm{C}$ are attributed to the decomposition of the residual oxygen-containing functional groups and the pyrolysis of the carbon skeleton from reduced graphene oxide, respectively ${ }^{54}$. The weight loss related to the removal of the oxygen functional groups from the $\mathrm{Pt} / \mathrm{RGO}$ is much lower than that for the GO. This indicates successful elimination of those groups during the solvothermal process. Basing on the TGA analysis, the content of $\mathrm{Pt}$ nanoparticles in the nanocomposite was estimated to be about $64 \mathrm{wt} \%$. 

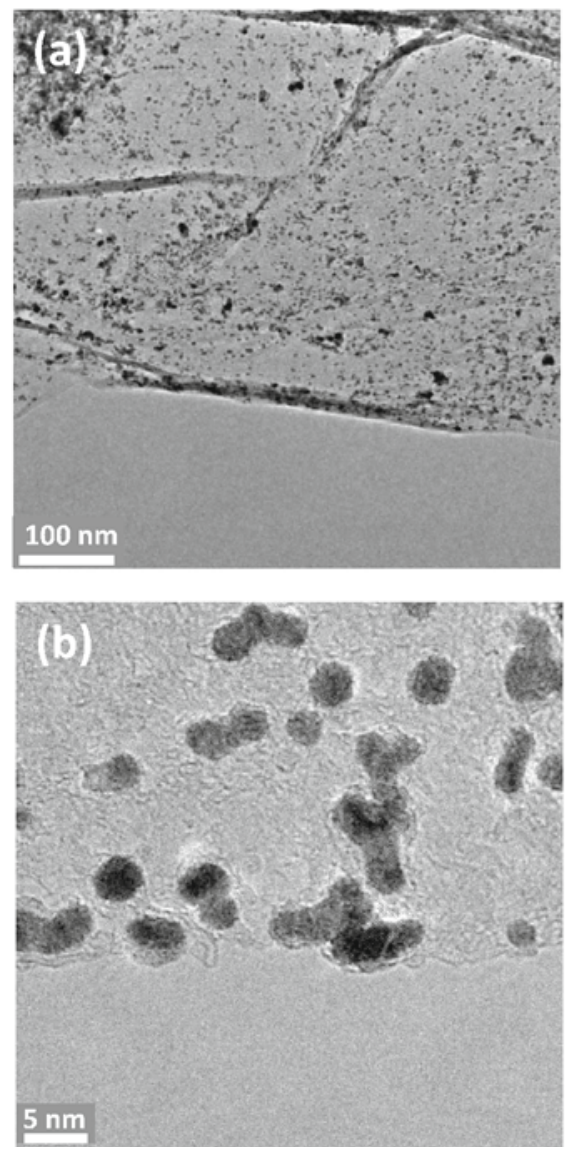

Figure 2. (a) and (b) TEM images, (c) XRD pattern,
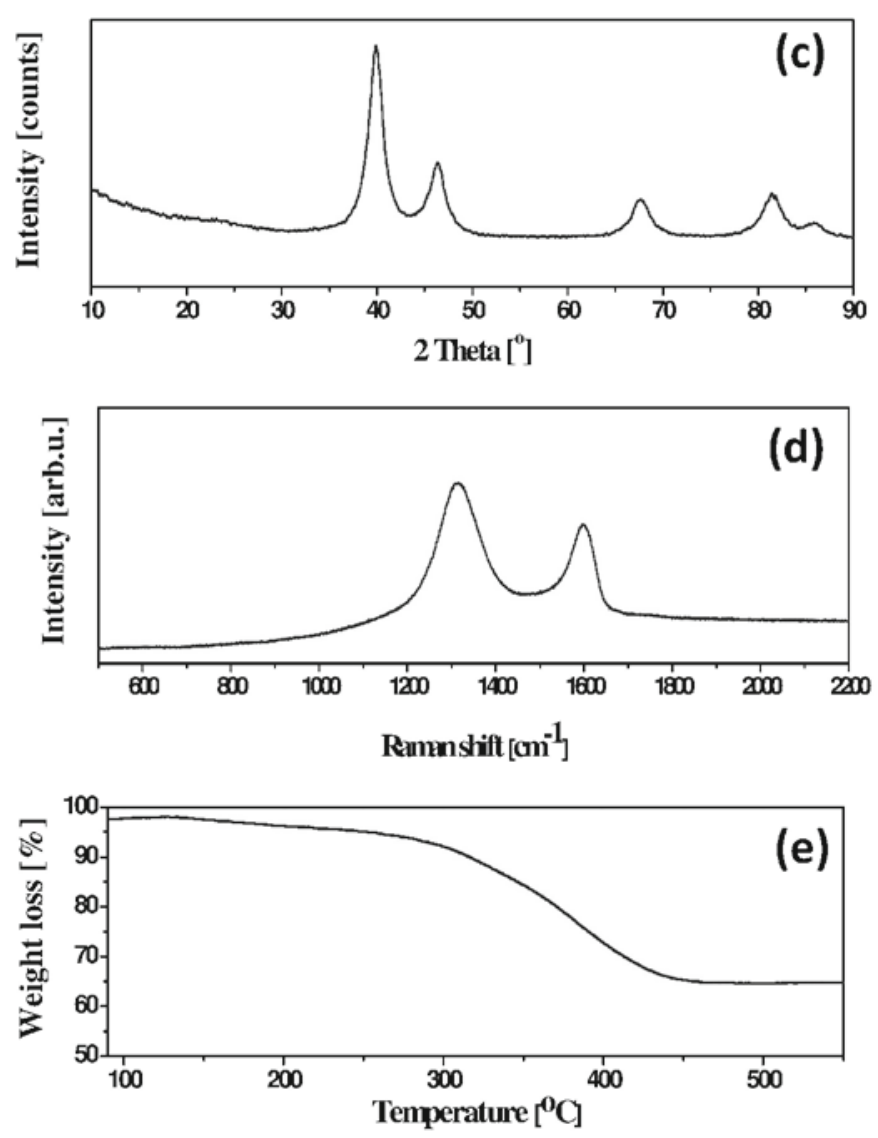

\section{Characterization of $\mathrm{MnO}_{2} / \mathrm{RGO}$ nanocomposite}

Morphology of the $\mathrm{MnO}_{2} / \mathrm{RGO}$ nanocomposite was analysed with transmission electron microscopy and images are shown in Figure 3(a) and (b). The nanocomposite consists of monodispersed nanospheres with diameters of $60 \pm 10 \mathrm{~nm}$ covered with reduced graphene oxide nanosheets. One can observe that $\mathrm{MnO}_{2}$ created honeycomb structure that was formed by the self-assembly of the nanoplatelets ${ }^{55}, 56$. The thickness of the nanoplatelets was established to be in the range of $2-4 \mathrm{~nm}$ which self-aligned perpendicular to the spherical surface and emanated from the centre (panel (b) of Fig. 3).

A phase and crystallographic structure of the prepared nanocomposite was analysed with X-ray diffraction technique and Raman spectroscopy, presented in Figure 3(c) and (d), respectively. XRD pattern of $\mathrm{MnO}_{2} / \mathrm{RGO}$ nanocomposite exhibits diffraction peaks at $2 \theta$ of $12.3^{\circ}$, $36.6^{\circ}, 41.9^{\circ}$ and $65.7^{\circ}$, attributed to (003), (101), (015) and (110) planes of hexagonal birnessite $\mathrm{MnO}_{2}{ }^{57}$. The broad peak at $2 \theta$ of approximately $24.6^{\circ}$ can be a result of the overlapping of (006) plane of $\mathrm{MnO}_{2}$ and (002) plane of the reduced graphene oxide. Raman spectrum, presented in Figure 3(d), shows three bands related to birnessitetype of $\mathrm{MnO}_{2}$, at around 503, 576, and $652 \mathrm{~cm}^{-1}$. The band at $576 \mathrm{~cm}^{-1}$ is attributed to the (Mn-O) stretching in the basal plane of the $\mathrm{MnO}_{6}$ sheet, while the feature at $652 \mathrm{~cm}^{-1}$ can be viewed as the symmetric stretching vibration $(\mathrm{Mn}-\mathrm{O})$ of the $\mathrm{MnO}_{6}$ octahedron in $\mathrm{MnO}_{2} \cdot \mathrm{H}_{2} \mathrm{O}^{58}$. Furthermore, Raman spectrum exhibits bands arising from the reduced graphene oxide detected at $1318 \mathrm{~cm}^{-1}$ and $1600 \mathrm{~cm}^{-1}$, corresponded to $\mathrm{D}$ and $\mathrm{G}$ band, respectively. The $\mathrm{I}_{\mathrm{D}} / \mathrm{I}_{\mathrm{G}}$ ratio was determined to
0.87 , which is much lower than that of GO (1.45). The decreased value can be attributed to reordering of the graphene structure during the thermal reduction of GO.

Figure 3(e) presents TGA curve of $\mathrm{MnO}_{2} / \mathrm{RGO}$ nanocomposite heated in air from the room temperature to $600^{\circ} \mathrm{C}$. A slight mass loss below $150^{\circ} \mathrm{C}$ originates from the vaporization of water. The releasing of the remaining oxygen-containing functional groups is detected at the temperature range of $150-300^{\circ} \mathrm{C}(3 \mathrm{wt} \%)$. Further increase of the temperature results in the pyrolysis of carbon skeleton. No weight loss is observed above $350^{\circ} \mathrm{C}$ indicating that the content of $\mathrm{MnO}_{2}$ in the nanocomposite is $82 \mathrm{wt} \%$.

\section{Characterization of Pd/RGO nanocomposite}

Transmission electron microscopy was used for the investigation of the morphology of the sample and the size distribution of palladium nanoparticles. Representative TEM images of Pd/RGO nanocomposite at different magnifications are presented in Figure 4(a) and 4(b). TEM images indicate an excellent and homogenous distribution of palladium nanoparticles on the surface of reduced graphene oxide flakes. The sample consists of the mixture of various shapes of palladium nanoparticles: spherical, triangular, cubic, hexagonal, rhomboidal, rod - like with broad size distribution (5 to $40 \mathrm{~nm}$ ).

After the decoration of the graphene flakes with palladium nanoparticles, a powder X-ray diffraction pattern (XRD) of the sample was recorded. Figure 4(c) presents XRD pattern of Pd/RGO nanocomposite. Five peaks indexed to the (111), (200), (220), (311), and (222) reflections of a face-centered cubic (fcc) structure of metallic Pd (JCPDS, card no. 05-0681) were 

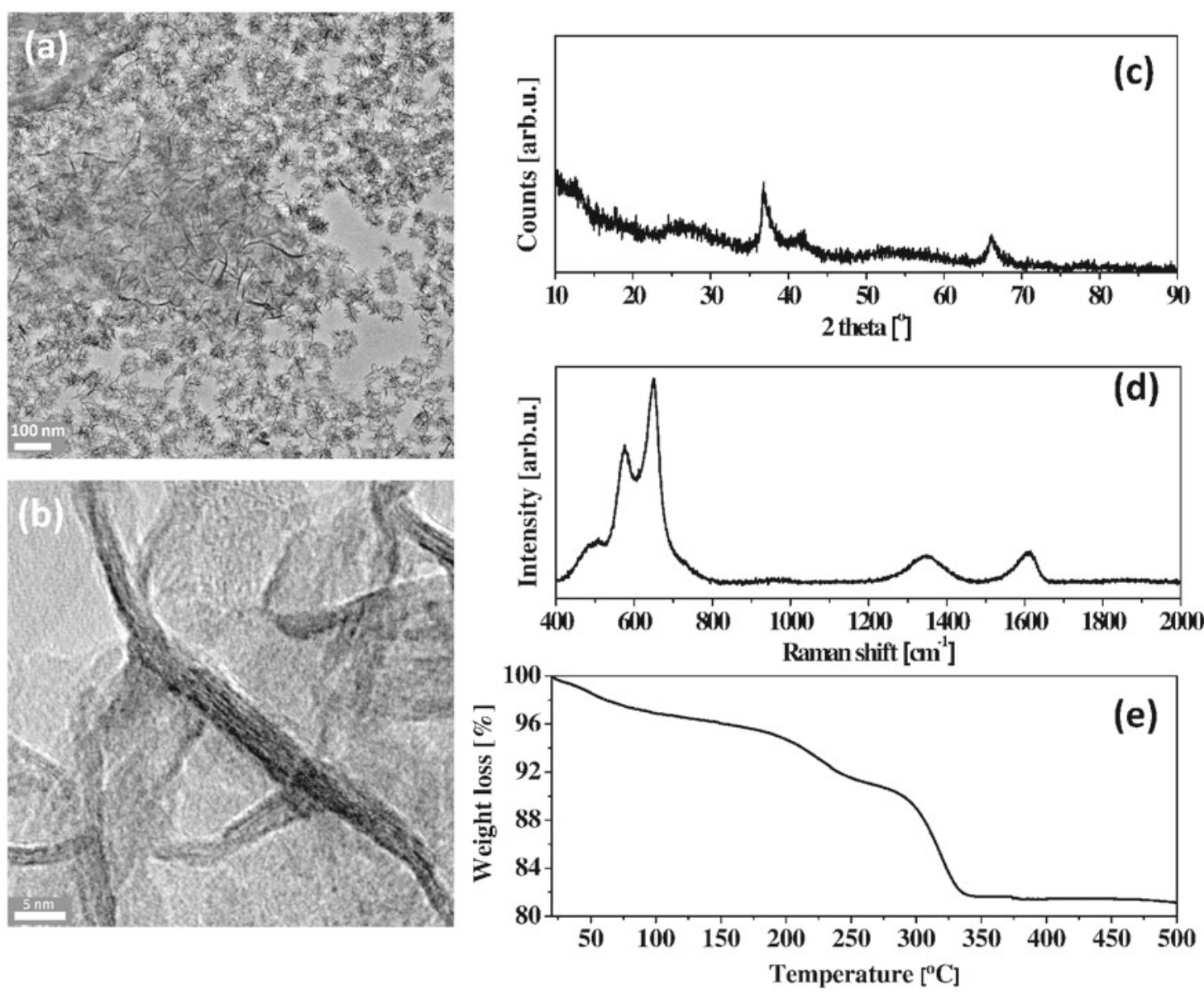

Figure 3. (a) and (b) TEM images, (c) XRD pattern, (d) Raman spectrum and (e) TGA curve of $\mathrm{MnO}_{2} / \mathrm{RGO}$ nanocomposite

noticed, showing the crystalline nature of the prepared nanoparticles. No obvious peaks from other phases are observed. The absence of a peak attributed to reduced graphene oxide may originate from its low crystallinity compared to palladium nanoparticles and its low content in the nanocomposite.

Figure 4(d) presents the TGA curve of Pd/RGO nanocomposite based on the weight loss during the heating in air. No significant weight loss between $120^{\circ} \mathrm{C}$ and $300^{\circ} \mathrm{C}$ is observed on TG curve of $\mathrm{Pd} / \mathrm{RGO}$ nanocomposite, suggesting the reduction of GO during the synthesis. However, the TGA analysis indicates the incomplete reduction of the functional groups because their $\sim 3$ wt $\%$ did not undergo the reduction. The sample contains approximately $55 \mathrm{wt} \%$ of palladium.

Figure 4(e) presents Raman spectrum of Pd/RGO nanocomposite. The spectrum exhibits peaks at 1311 and $1601 \mathrm{~cm}^{-1}$, corresponded to $\mathrm{D}$ and $\mathrm{G}$ bands, respectively. The intensity ratio $\mathrm{I}_{\mathrm{D}} / \mathrm{I}_{\mathrm{G}}$ of $\mathrm{GO}$ increases after the deposition of palladium nanoparticles $\left(\mathrm{I}_{\mathrm{D}} / \mathrm{I}_{\mathrm{G}}=2.11\right)$.

\section{Characterization of $\mathrm{ZrO}_{2} / \mathrm{RGO}$ nanocomposite}

Transmission electron microscopy was applied to explore the structure of the sample and the size and shape of the deposited nanoparticles. Figure 5(a) and (b) present TEM images of $\mathrm{ZrO}_{2} / \mathrm{RGO}$ nanocomposite at different magnifications from which the flower-like morphology of zirconium dioxide of sizes of 10-20 nm can be observed. One can also notice a homogenous distribution of $\mathrm{ZrO}_{2}$ on the graphene platform.
Powder X-ray diffraction technique is a useful tool to characterize the crystal structure of the samples. Figure 5(c) shows the XRD pattern of $\mathrm{ZrO}_{2} / \mathrm{RGO}$ nanocomposite. Four strong diffraction peaks at $30^{\circ}, 35^{\circ}, 50^{\circ}$ and $60^{\circ}$ arising from (111), (200), (220), and (311) diffraction planes of the tetragonal zirconia (card no.79-1771) have been detected. Any other obvious peaks have not been recorded.

In order to investigate the thermal behavior of the sample and to estimate the content of the residual functional groups and the amount of zirconia in the sample, TG analysis was performed (Fig. 5(d)). During the synthesis the starting material was reduced what is indicated by very small mass loss $(4 \mathrm{wt} \%)$ in the temperature range of $120-300^{\circ} \mathrm{C}$. The content of zirconia in the nanocomposite has been estimated for $\sim 60 \mathrm{wt} \%$.

Figure 5(e) depicts Raman spectra of $\mathrm{ZrO}_{2} / \mathrm{RGO}$ nanocomposite. The peaks from $\mathrm{D}$ and $\mathrm{G}$ bands, appeared at 1313 and $1599 \mathrm{~cm}^{-1}$ have been observed, respectively. The intensity ratio $I_{D} / I_{G}$ of RGO decreases to the value of 1.39 after the decoration of graphene platform with zirconia indicating partial restoration of sp2domains during the functionalization process.

\section{DISCUSSION}

An extremely powerful tool facilitating characterization of graphene-based materials, including graphene oxide, reduced graphene oxide and their composites with metals and metals oxides, is Raman spectroscopy as a fast, non-destructive and high-resolution method for examination of their fundamental physical properties. Hence, we 

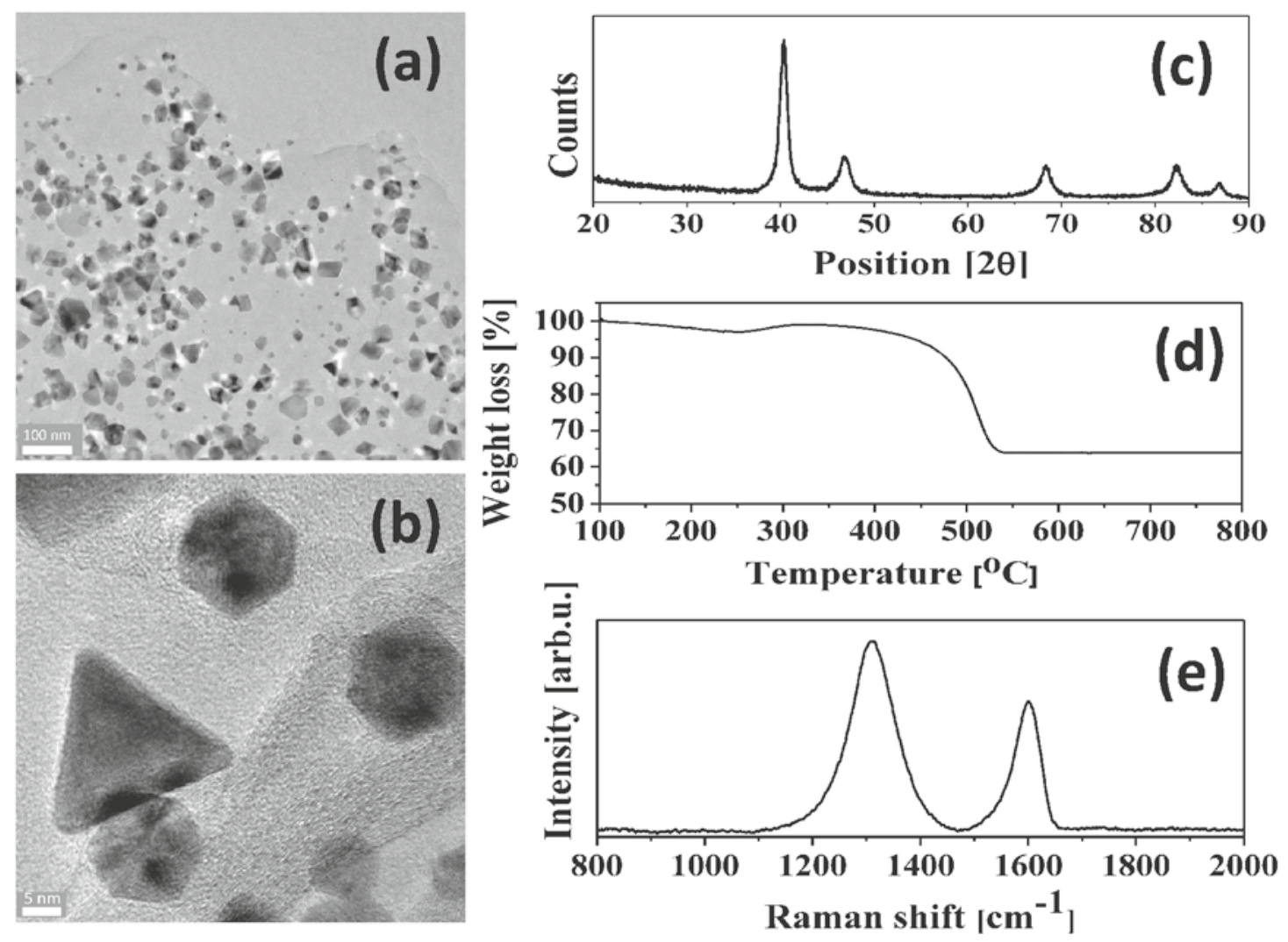

Figure 4. (a) and (b) TEM images, (c) XRD pattern, (d) TGA curve and (e) Raman spectrum of Pd/RGO nanocomposite
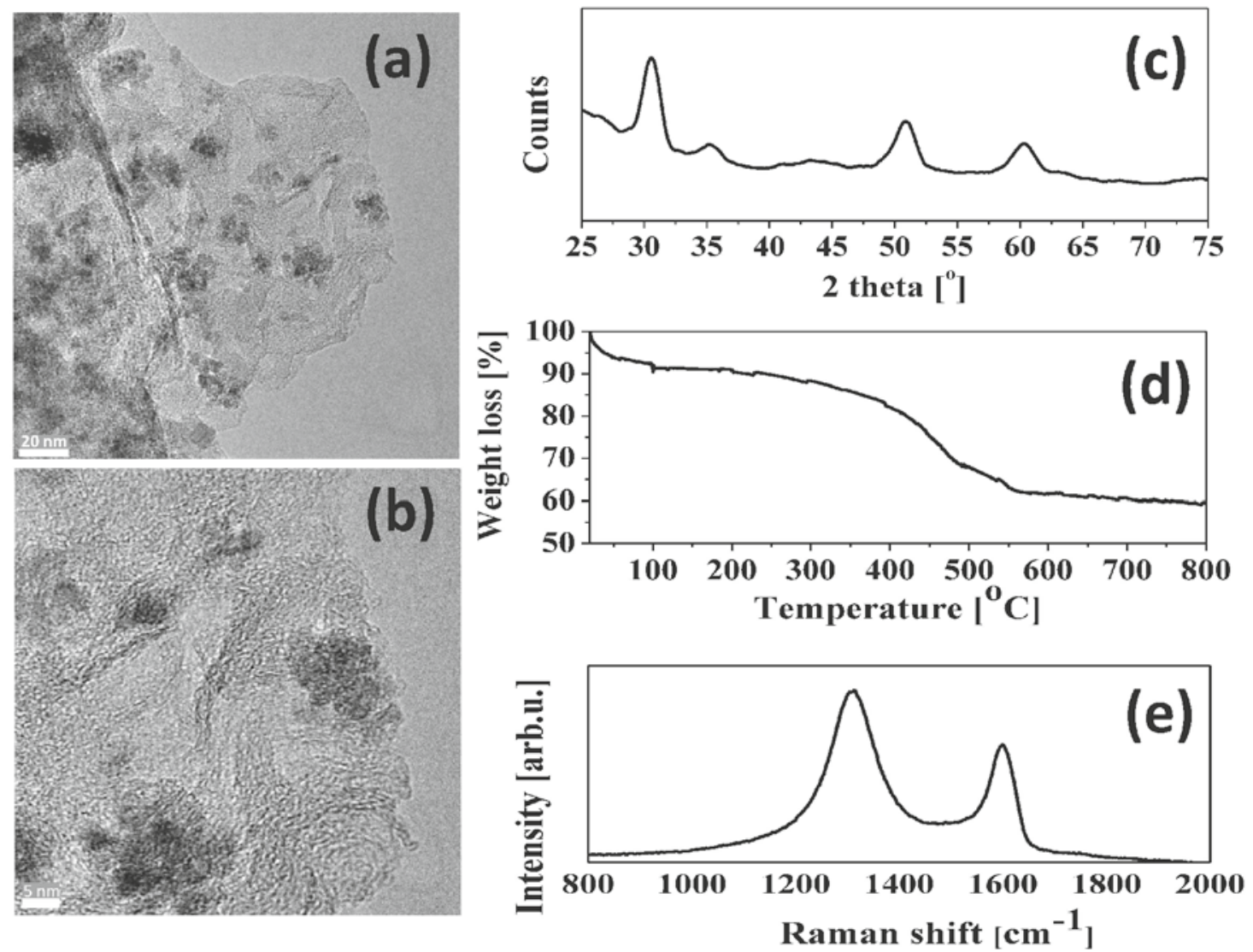

Figure 5. (a) and (b) TEM images, (c) XRD pattern, (d) TGA curve and (e) Raman spectrum of $\mathrm{ZrO}_{2} / \mathrm{RGO}$ nanocomposite

utilized Raman spectroscopy to study reduced graphene oxide-nanocomposites in terms of the structural defects and doping of RGO. Table 1 summarizes Raman peaks positions (D, G and $2 \mathrm{D}), \mathrm{I}_{\mathrm{D}} / \mathrm{I}_{\mathrm{G}}$ ratios and full width at half maximum (FWHM) of $\mathrm{G}$ band of graphene oxide and the each nanocomposite. One can see that $\mathrm{G}$ band of GO appears at $1598 \mathrm{~cm}^{-1}$, which is upshifted compared to graphite as a results of oxidation. On the other hand, when graphene oxide undergoes reduction, the $\mathrm{G}$ band shifts back near the position of the starting graphite ${ }^{59}$. This effect has been reported in both chemical and thermal reduction of $\mathrm{GO}^{60}$. However, in case of the $\mathrm{Pt} / \mathrm{RGO}, \mathrm{Pd} /$ 
Table 1. Positions of $\mathrm{D}, \mathrm{G}$ and $2 \mathrm{D}$ bands, intensity ratio of $\mathrm{D}$ and $\mathrm{G}$ bands (ID/IG) and FWHM of G bands of graphene oxide, Pt/ $\mathrm{RGO}, \mathrm{Pd} / \mathrm{RGO}, \mathrm{MnO}_{2} / \mathrm{RGO}$ and $\mathrm{ZrO}_{2} / \mathrm{RGO}$

\begin{tabular}{|c|c|c|c|c|c|}
\hline Sample & $\mathrm{D}$ band $\left[\mathrm{cm}^{-1}\right]$ & $\mathrm{G}$ band $\left[\mathrm{cm}^{-1}\right]$ & 2D band $\left[\mathrm{cm}^{-1}\right]$ & $\mathrm{I}_{\mathrm{D}} / \mathrm{I}_{\mathrm{G}}$ & $\mathrm{FWHM}_{\mathrm{G} \text { band }}$ \\
\hline $\mathrm{GO}$ & 1310 & 1598 & 2591 & 1.45 & 58 \\
\hline $\mathrm{Pt} / \mathrm{RGO}$ & 1314 & 1596 & $x$ & 1.43 & 56 \\
\hline $\mathrm{Pd} / \mathrm{RGO}$ & 1311 & 1601 & $x$ & 2.11 & 53 \\
\hline $\mathrm{ZrO}_{2} / \mathrm{RGO}$ & 1313 & 1599 & $x$ & 1.39 & 52 \\
\hline
\end{tabular}

$\mathrm{RGO}, \mathrm{MnO}_{2} / \mathrm{RGO}$ and $\mathrm{ZrO}_{2} / \mathrm{RGO}$ nanocomposites the $\mathrm{G}$ bands are located at 1596, 1601, 1600 and $1599 \mathrm{~cm}^{-1}$, respectively, which are still blue-shifted in comparison to graphite. The upshifting of $\mathrm{G}$ band might be associated with the doping of graphene, already confirmed experimentally by many researchers ${ }^{\mathbf{6 1 - 6 6}}$. Moreover, the doping of graphene influences the reduction of the FWHM of the $\mathrm{G}$ peak, as it was reported by Das et al. and Iqbal et al. ${ }^{\mathbf{6 3}, \mathbf{6 7}}$. Here, each nanocomposite exhibits FWHM of the $\mathrm{G}$ band lower than that of graphene oxide, indicating the doping of graphene upon the deposition of $\mathrm{Pt}, \mathrm{Pd}$, $\mathrm{MnO}_{2}$ and $\mathrm{ZrO}_{2}$, respectively.

The values of $\mathrm{I}_{\mathrm{D}} / \mathrm{I}_{\mathrm{G}}$ ratio indicates that the level of disorder of reduced graphene oxide in $\mathrm{Pt} / \mathrm{RGO}$ and $\mathrm{ZrO}_{2} / \mathrm{RGO}$ is similar to that of graphene oxide which might be related to replacement of the vacancies formed during the reduction of GO by the nanoparticles. Conversely, the nanocomposites $\mathrm{Pd} / \mathrm{RGO}$ and $\mathrm{MnO}_{2} /$ RGO show much higher (2.11) and lower (0.87) $\mathrm{I}_{\mathrm{D}} / \mathrm{I}_{\mathrm{G}}$ ratios than graphene oxide, respectively. The decreased $\mathrm{I}_{\mathrm{D}} / \mathrm{I}_{\mathrm{G}}$ ratio of $\mathrm{MnO}_{2} / \mathrm{RGO}$ might be attributed to two possible behaviors. Firstly, there is a regime of "low" defect density where $\mathrm{I}_{\mathrm{D}} / \mathrm{I}_{\mathrm{G}}$ will increase until a regime of "high" defect density, at which point $\mathrm{I}_{\mathrm{D}} / \mathrm{I}_{\mathrm{G}}$ will begin to decrease as an increasing defect density results in more amorphous carbon structure, attenuating all Raman peaks $^{68}$. Though, the other reason is that reduction of graphene oxide resulted in the restoration of the ordered graphene structure. The enhanced $\mathrm{I}_{\mathrm{D}} / \mathrm{I}_{\mathrm{G}}$ value of $\mathrm{Pd} / \mathrm{RGO}$ Raman spectrum could be associated with the strong chemical interaction between palladium and RGO. The Raman spectroscopy analysis showed that type of metal/ metal oxide nanoparticles strongly influences the level of the reduced graphene oxide doping and disordering.

\section{SUMMARY}

The paper presents methods of reduced graphene oxide functionalization with platinum, palladium, manganese dioxide and zirconium dioxide nanoparticles. The functionalization of $\mathrm{RGO}$ with $\mathrm{Pt}, \mathrm{Pd}$ and $\mathrm{ZrO}_{2}$ was carried using solvothermal reduction of the nanoparticles precursors, while creation of $\mathrm{MnO}_{2}$ nanospheres with simultaneous deposition on RGO underwent in oleic/ water interface. The nanocomposites were characterized with transmission electron microscope, XRD, TGA and Raman spectroscopy. The content of the nanoparticles was $64 \mathrm{wt} \%, 55 \mathrm{wt} \%, 60 \mathrm{wt} \%$ and $82 \mathrm{wt} \%$ in $\mathrm{Pt} / \mathrm{RGO}$, $\mathrm{Pd} / \mathrm{RGO}, \mathrm{MnO}_{2} / \mathrm{RGO}$ and $\mathrm{ZrO}_{2} / \mathrm{RGO}$, respectively. Raman spectroscopy analysis indicated doping of RGO with the nanoparticles, and, depending on the type of nanoparticles, RGO showed various level of doping and disorder.

\section{ACKNOWLEDGEMENTS}

The authors are grateful for the financial support from National Center for Research and Development, no. GRAF-TECH/NCBR/08/06/2013.

\section{LITERATURE CITED}

1. Geim, A.K. \& Novoselov, K.S. (2007). The rise of graphene. Nat. Mater. 6, 183-191. DOI: 10.1038/nmat1849.

2. Katsnelson, M.I. (2007). Graphene: carbon in two dimensions. Mater. Today 10, 20-27. DOI: 10.1016/S13697021(06)71788-6.

3. Loh, K.P., Bao, Q., Ang, P.K. \& Yang, J. (2010). The chemistry of graphene. J. Mater. Chem. 20, 2277-2289. DOI: 10.1039/b920539j.

4. Loh, K.P., Bao, Q., Eda, G. \& Chhowalla, M. (2010). Graphene oxide as a chemically tunable platform for optical applications. Nat. Chem. 2, 1015-1024. DOI: 10.1038/ nchem.907.

5. Lerf, A., He, H. \& Forster, M. (1998). Structure of graphite oxide revisited. J. Phys. Chem. B. 102, 4477-4482. DOI: 10.1021/jp9731821.

6. Wang, S., Goh, B.M., Manga, K.K., Bao, Q., Yang, P. \& Loh, K.P. (2010). Graphene as Atomic Template and Structural Scaffold in the Synthesis of Graphene-Organic Hybrid Wire with Photovoltaic Properties. ACS Nano 4, 6180-6186. DOI: 10.1021/nn101800n.

7. Hu, H., Allan, C.C. K., Li, J., Kong, Y., Wang, X., Xin, J. H. \& Hu, H. (2014). Multifunctional organically modified graphene with super-hydrophobicity. Nano Res. 7, 418-433. DOI: 10.1007/s12274-014-0408-0.

8. Muszynski, R., Seger, B. \& Kamat, P.V. (2008). Decorating Graphene Sheets with Gold Nanoparticles. J. Phys. Chem. C 112, 5263-5266. DOI: 10.1021/jp800977b.

9. Zhu, J., Zhu, T., Zhou, X, Zhang, Y., Lou, X.W., Chen, X., Chen, H., Zhang, H., Hng, H.H., Ma, J. \& Yan, Q. (2011). Facile synthesis of metal oxide/reduced graphene oxide hybrids with high lithium storage capacity and stable cyclability. Nanoscale 3, 1084-1089. DOI: 10.1039/C0NR00744G.

10. Ling, Q., Yang, M., Li, C.S. \& Zhang, A.M. (2015). Preparation of Monolayered Ce-Fe Oxides Dispersed on Graphene and Their Superior Adsorptive Behavior, Fuller. Nanotub. Car. N. 23, 158-164. DOI: 10.1080/1536383X.2013.863759.

11. Li, C.X., Hu, C.G., Zhao, Y., Song, L., Zhang, J., Huang, R.D. \& Qu, L.T. (2014). Decoration of graphene network with metal-organic frameworks for enhanced electrochemical capacitive behavior, Carbon 78, 231-242. DOI: 10.1016/j. carbon.2014.06.076.

12. Lu, C.H., Yang, H.H., Zhu, C.L., Chen, X. \& Chen, G.N. (2009). Angew. Chem. Int. Ed. 121, 4879-4881. DOI: 10.1002/ ange. 200901479

13. Huang, J., Zheng Q., Kim, J.K. \& Li, Z. (2013). A molecular beacon and graphene oxide-based fluorescent biosensor for $\mathrm{Cu}^{2+}$ detection. Biosens. Bioelectron. 43, 379-383. DOI: 10.1016/j.bios.2012.12.056.

14. Fan, Z., Yan, J., Zhi, L., Zhang, Q., Wei, T., Feng, J., Zhang, M., Qian W. \& Wei, F. (2010). A Three-Dimensional Carbon Nanotube/Graphene Sandwich and Its Application as Electrode in Supercapacitors. Adv. Mater. 22, 3723-3728. DOI: $10.1002 /$ adma.201001029. 
15. Lim, S., Kang, B., Kwak, D., Lee, W.H., Lim, J.A. \& Cho, K. (2012). Inkjet-Printed Reduced Graphene Oxide/ Poly(VinylAlcohol) Composite Electrodes for Flexible Transparent Organic Field-Effect Transistors. J. Phys. Chem. C. 116, 7520-7525. DOI: 10.1021/jp203441e.

16. Dixon, D., Lemonine, P., Hamilton, J., Lubarsky, G. \& Archer, E. (2015). Graphene oxide-polyamide 6 nanocomposites produced via in situ polymerization. J. Thermoplast. Compos. 28, 372-389. DOI: 10.1177/0892705713484749.

17. Wojtoniszak, M., Urbas, K., Peruzynska, M., Kurzawski, M., Drozdzik, M. \& Mijowska, E. (2013). Covalent conjugation of graphene oxide with methotrexate and its antitumor activity, Chem. Phys. Lett. 568, 151-156. DOI: 10.1016/j. cplett.2013.03.050.

18. Liu, H., Ryu, S., Chen, Z., Steigerwald, M.L., Nuckolls, C. \& Brus, L.E. (2009). Photochemical Reactivity of Graphene.J. Am. Chem. Soc. 131, 17099-17101. DOI: 10.1021/ja9043906.

19. Zhu, J., Zhu, T., Zhou, X., Zhang, Y., Lou, X.W., Chen, X., Chen, H., Zhang, H., Hng, H.H., Ma, J. \& Yan, Q. (2011). Facile synthesis of metal oxide/reduced graphene oxide hybrids with high lithium storage capacity and stable cyclability. Nanoscale 3, 1084-1089. DOI: 10.1039/ C0NR00744G.

20. Shi, W., Zhu, J., Sim, D.H., Tay, Y.Y., Lu, Z.Y., Zhang, X.J., Zhang, H., Hng, H.H. \& Yan, Q.Y. (2011). Achieving high specific charge capacitances in $\mathrm{Fe}_{3} \mathrm{O}_{4} /$ reduced graphene oxide nanocomposites. J. Mater. Chem. 21, 3422-3427. DOI: 10.1039/C0JM03175E.

21. Li, Y., Tang, L. \& Li, J. (2009). Preparation and electrochemical performance for methanol oxidation of $\mathrm{Pt} / \mathrm{graphene}$ nanocomposites. Electrochem. Commun. 11, 846-849. DOI: 10.1016/j.elecom.2009.02.009.

22. Xie, L, Ling, X., Fang, Y., Zhang, J. \& Liu, Z. (2009). Graphene as a substrate to suppress fluorescence in resonance Raman spectroscopy. J. Am. Chem. Soc. 131, 9890-9891. DOI: $10.1021 /$ ja9037593.

23. Zhou, X., Huang, X., Qi, X., Wu, S., Xue, C., Boey, F.Y.C., Yan, Q., Chen, P. \& Zhang, H. (2009). In situ synthesis of metal nanoparticles on single-layer graphene oxide and reduced graphene oxide surfaces. J. Phys. Chem. C 113, 10842-10846. DOI: 10.1021/jp903821n.

24. Liu, J.B., Fu, S.H., Yuan, B., Li, Y.L. \& Deng, Z.X. (2010). Toward a universal "adhesive nanosheet" for the assembly of multiple nanoparticles based on a protein-induced reduction/decoration of graphene oxide. J. Am. Chem. Soc. 132, 7279-7281. DOI: $10.1021 /$ ja100938r.

25. Shen, J.F., Shi, M., Li, N., Yan, B., Ma, H.W., Hu, Y.Z., \& Ye, M.X. (2010). Facile synthesis and application of Ag-chemically converted graphene nanocomposite. Nano Res. 3, 339-349. DOI: 10.1007/s12274-010-1037-x.

26. Scheuermann, G.M., Rumi, L., Steurer, P., Bannwarth, W. \& Mulhaupt, R. (2009). Palladium nanoparticles on graphite oxide and its functionalized graphene derivatives as highly active catalysts for the Suzuki-Miyaura coupling reaction. $J$. Am. Chem. Soc. 131, 8262-8270. DOI: 10.1021/ja901105a.

27. Johnson, J.L., Behnam, A., Pearton, S.J. \& Ural, A. (2010). Hydrogen Sensing Using Pd-Functionalized Multi-Layer Graphene Nanoribbon Networks. Adv. Mater. 22, 4877-4880. DOI: 10.1002/adma.201001798.

28. Si, Y.C. \& Samulski, E.T. (2008). Exfoliated Graphene Separated by Platinum Nanoparticles. Chem. Mater. 20, 6792-6797. DOI: 10.1021/cm801356a.

29. Hassan, H.M.A., Abdelsayed, V., Khder, A., AbouZeid, K. M., Terner, J., El-Shall, M.S., Al-Resayes, S.I., El-Azhary, A.A. (2009). Microwave synthesis of graphene sheets supporting metal nanocrystals in aqueous and organic media. J. Mater. Chem. 19, 3832-3837. DOI: 10.1039/b906253j.

30. Pavithra, C.L.P., Sarada, B.V., Rajulapati, K.V., Rao, T.N. \& Sundararajan, G. (2014). A New Electrochemical Approach for the Synthesis of Copper-Graphene Nanocom- posite Foils with High Hardness. Sci. Rep. 4, 4049. DOI: 10.1038/srep04049.

31. Ji, Z., Shen, X., Zhu, G., Zhou, H. \& Yuan, A. (2012). Reduced graphene oxide/nickel nanocomposites: facile synthesis, magnetic and catalytic properties. J. Mater. Chem. 22, 3471-3477. DOI: 10.1039/C2JM14680K.

32. Liu, J., Bai, H., Wang, Y., Liu, Z., Zhang, X. \& Sun, D.D. (2010). Self-Assembling $\mathrm{TiO}_{2}$ Nanorods on Large Graphene Oxide Sheets at a Two-Phase Interface and Their Anti-Recombination in Photocatalytic Applications. $A d v$. Funct. Mater. 20, 4175-4181. DOI: 10.1002/adfm.201001391.

33. Du, J., Lai, X., Yang, N., Zhai, J., Kisailus, D., Su, F., Wang, D. \& Jiang, L. (2010). Hierarchically Ordered Macro-Mesoporous $\mathrm{TiO}_{2}$-Graphene Composite Films: Improved Mass Transfer, Reduced Charge Recombination, and Their Enhanced Photocatalytic Activities. ACS Nano 5, 590-596. DOI: 10.1021/nn102767d.

34. Yin, Z., Wu, S., Zhou, X., Huang, X., Zhang, Q., Boey, F. \& Zhang, H. (2010). Electrochemical Deposition of ZnO Nanorods on Transparent Reduced Graphene Oxide Electrodes for Hybrid Solar Cells. Small 6, 307-312. DOI: 10.1002/smll.200901968.

35. Zhang, L.S., Jiang, L.Y., Yan, H.J., Wang, W.D., Wang, W., Song, W.G., Guo, Y.G. \& Wan, L.J. (2010). Monodispersed $\mathrm{SnO}_{2}$ Nanoparticles on both Sides of Single Layer Graphene Sheets as Anode Materials in Li-ion Batteries. J. Mater. Chem. 20, 5462-5467. DOI: 10.1039/C0JM00672F.

36. Yan, J., Fan, Z., Wei, T., Qian, W., Zhang, M. \& Wei, F. (2010). Fast and reversible surface redox reaction of graphene- $\mathrm{MnO}_{2}$ composites as supercapacitor electrodes. Carbon 48, 3825-3833. DOI: 10.1016/j.carbon.2010.06.047.

37. Yang, X., Zhang, X., Ma, Y., Huang, Y., Wang, Y. \& Chen, Y. (2009). Superparamagnetic graphene oxide- $-\mathrm{Fe}_{3} \mathrm{O}_{4}$ nanoparticles hybrid for controlled targeted drug carriers. J. Mater. Chem. 19, 2710-2714. DOI: 10.1039/b821416f.

38. Liang, J., Xu, Y., Sui, D., Zhang, L., Huang, Y., Ma, Y., Li, F. \& Chen, Y. (2010). Flexible, magnetic, and electrically conductive graphene $/ \mathrm{Fe}_{3} \mathrm{O}_{4}$ paper and its application for magnetic-controlled switches. J. Phys. Chem. C 114, 17465-17471. DOI: 10.1021/jp105629r.

39. Innocenzi, P., Malfatti, L., Lasio, B., Pinna, A., Loche, D., Casula, M.F., Alzari, V. \& Mariani, A. (2014). Sol-gel chemistry for graphene-silica nanocomposite films. New J. Chem. 38, 3777-3782. DOI: 10.1039/C4NJ00535J.

40. Jiang, N., Xiu, Z., Xie, Z., Li, H., Zhao, G., Wang, W., Wu, Y. \& Hao, X. (2014). Reduced graphene oxide-CdS nanocomposites with enhanced visible-light photoactivity synthesized using ionic-liquid precursors. New J. Chem. 38, 4312-4320. DOI: 10.1039/C4NJ00152D.

41. Lin, Y., Zhang, K., Chen, W., Liu, Y., Geng, Z., Zeng, J., Pan, N., Yan, L., Wang, X. \& Hou, J.G. (2010). Dramatically enhanced photoresponse of reduced graphene oxide with linker-free anchored CdSe nanoparticles. ACS Nano 4, 3033-3038. DOI: 10.1021/nn100134j.

42. Allen, M.J., Tung, V.C. \& Kaner, R.B. (2009). Honeycomb carbon: a review of graphene. Chem. Rev. 110, 132-145. DOI: $10.1021 /$ cr900070d.

43. Marcano, D.C., Kosynkin, D.V., Berlin, J.M., Sinitskii, A., Sun, Z., Slesarev, A., Alemany, L.B., Lu, W. \& Tour, J.M. (2010). Improved synthesis of graphene oxide. ACS Nano 4, 4806-4814. DOI: 10.1021/nn1006368.

44. Sun, Z., Rong, Z., Wang, Y., Xia, Y., Du, W. \& Wang, Y. (2014). Selective hydrogenation of cinnamaldehyde over Pt nanoparticles deposited on reduced graphene oxide. RSC Adv. 4, 1874-1878. DOI: 10.1039/C3RA44962A.

45. Some, S., Kim, Y., Yoon, Y., Yoo, H.J., Lee, S., Park, Y. \& Lee, H. (2013). High-quality reduced graphene oxide by a dual-function chemical reduction and healing process. Sci. Rep. 3, 1-5. DOI:10.1038/srep01929. 
46. Satish, B., Venkateswara, R.K., Shilpa, C.C.H. \& Tejaswi, T. (2013). Synthesis and characterization of graphene oxide and its antimicrobial activity against Klebseilla and Staphylococus. Int. J. Adv. Biotechnol. Res. 4, 142-146.

47. Reich, S.S. \& Thomsen, C. (2004). Raman spectroscopy of graphite. Phil. Trans. R. Soc. Lond. A 362, 2271-2288. DOI: 10.1098/rsta.2004.1454.

48. Kudin, K.N., Ozbas, B., Schniepp, H.C., Prudhomme, R.K., Aksay, I.A. \& Car, R. (2008). Raman spectra of graphite oxide and functionalized graphene sheets. Nano Lett. 8, 36-41. DOI: $10.1021 / \mathrm{nl071822y.}$

49. Charlier, J.C., Eklund, P.C., Zhu, J. \& Ferrari, A.C. (2008). Electron and phonon properties of graphene: their relationship with carbon nanotubes. Top Appl. Phys. 111, 673-709. DOI: $10.1007 / 978-3-540-72865-821$.

50. Kumar, P.V., Bardhan, N.M., Tongay, S., Wu, J., Belcher, A.M. \& Grossman, J.C. (2014). Scalable enhancement of graphene oxide properties by thermally driven phase transformation. Nat. Chem. 6, 151-158. DOI: 10.1038/ nchem.1820.

51. Fan, Z.J., Kai, W., Yan, J., Wei, T., Zhi, L.J., Feng, J., Ren, Y.M., Song, L.P. \& Wei, F. (2011). Facile synthesis of graphene nanosheets via $\mathrm{Fe}$ reduction of exfoliated graphite oxide. ACS Nano 5, 191-198. DOI: 10.1021/nn102339t.

52. Hyde, T. (2008). Crystallite Size Analysis of Supported Platinum Catalysts by XRD. Platinum Metals Rev. 52, 129-130. DOI: 10.1595/147106708X299547.

53. Liu, S., Wang, J., Zeng, J., Ou, J., Li, Z., Liu, X. \& Yang, S. (2010). „Green” electrochemical synthesis of Pt/graphene sheet nanocomposite film and its electrocatalytic property. J. Pow. Sour. 195, 4628-4633. DOI: 10.1016/j. jpowsour.2010.02.024.

54. Ganguly, A., Sharma, S., Papakonstantinou, P. \& Hamilton, J. (2011). Probing the Thermal Deoxygenation of Graphene Oxide Using High-Resolution In Situ X-ray-Based Spectroscopies. J. Phys. Chem. 115, 17009-17019. DOI: 10.1021/jp203741y.

55. Yuan, J.K., Li, W.N., Gomez, S. \& Suib, S.L. (2005). Shape-Controlled Synthesis of Manganese Oxide Octahedral Molecular Sieve Three-Dimensional Nanostructures. J. Am. Chem. Soc. 127, 14184-14185. DOI: 10.1021/ja053463j.

56. Yuan, J., Laubernds, K., Zhang, Q. \& Suib, S.L. (2003). Self-assembly of microporous manganese oxide octahedral molecular sieve hexagonal flakes into mesoporous hollow nanospheres. J. Am. Chem. Soc. 125, 4966-4967. DOI: $10.1021 / \mathrm{ja} 0294459$.

57. Li, Z., Wang, J., Wang, Z., Ran, H., Yang Li, Y., Han, X. \& Yang, S. (2012). Synthesis of a porous birnessite manganese dioxide hierarchical structure using thermally reduced graphene oxide paper as a sacrificing template for supercapacitor application. New J. Chem. 36, 1490-1495. DOI: $10.1039 / \mathrm{c} 2$ nj21052e.

58. Gui, Z., Gillette, E., Duay, J., Hu, J., Kim, N. \& Lee, S. B. (2015). Co-electrodeposition of $\mathrm{RuO}_{2}-\mathrm{MnO}_{2}$ nanowires and the contribution of $\mathrm{RuO}_{2}$ to the capacitance increase. Phys. Chem. Chem. Phys. 17, 15173-15180. DOI: 10.1039/ C5CP01814E.

59. Abdolhosseinzadeh, S., Asgharzadeh, H., \& Kim, H.S. (2015). Fast and fully-scalable synthesis of reduced graphene oxide. Sci. Rep. 5, 1-7. DOI: 10.1038/srep10160.

60. Stankovich, S., Dikina, D.A., Pinera, R.D., Kohlhaasa, K. A., Kleinhammesc, A., Jiac, Y., Wuc, Y., Nguyenb, S.T. \& Ruoff, R.S. (2007). Synthesis of graphene-based nanosheets via chemical reduction of exfoliated graphite oxide. Carbon 45, 1558-1565. DOI: 10.1016/j.carbon.2007.02.034.

61. Kalbac, M., Reina-Cecco, A., Farhat, H., Kong, J., Kavan, L. \& Dresselhaus, M.S. (2010). The influence of strong electron and hole doping on the Raman intensity of chemical vapor-deposition graphene. ACS Nano 4, 6055-6063. DOI: 10.1021/nn1010914.
62. Casiraghi, C. (2009). Probing disorder and charged impurities in graphene by Raman spectroscopy. Phys. Status Solidi. 3, 175-177. DOI: 10.1002/pssr.200903135.

63. Das, A., Pisana, S., Chakraborty, B., Piscanec, S., Saha, S.K., Waghmare, U.V., Novoselov, K.S., Krishnamurthy, H.R., Geim, A.K., Ferrari, A.C. \& Sood, A.K. (2008). Monitoring dopants by Raman scattering in an electrochemically topgated graphene transistor. Nature Nanotechnol. 3, 210-215. DOI: 10.1038/nnano.2008.67.

64. Heydrich, S., Hirmer, M., Preis, C., Korn, T., Eroms, J., Weiss, D. \& Schüller, C. (2010). Scanning Raman spectroscopy of graphene antidot lattices: evidence for systematic p-type doping. Appl. Phys. Lett. 97, 043113-1. DOI: 10.1063/1.3474613.

65. Lee, J., Novoselov, K.S. \& Shin, H.S. (2011). Interaction between metal and graphene: dependence on the layer number of graphene. ACS Nano 5, 608-612. DOI: 10.1021/ $\mathrm{nn} 103004 \mathrm{c}$.

66. Wang, W.X., Liang, S.H., Yu, T., Li, D.H., Li, Y.B. \& Han, X.F. (2011). The study of interaction between graphene and metals by Raman spectroscopy. J. Appl. Phys. 109, 07C501-07C501-3. DOI: 10.1063/1.3536670.

67. Iqbal, M.W., Singh, A.K., Iqbal, M.Z. \& Eom, J. (2012). Raman fingerprint of doping due to metal adsorbates on graphene. J. Phys.: Condens. Matter. 24, 335301-335308. DOI: $10.1088 / 0953-8984 / 24 / 33 / 335301$.

68. Lucchese, M.M., Stavale, F., Ferreira, E.H., Vilani, C., Moutinho, M.V.O., Capaz, R.B., Achete, C.A. \& Jorio, A. (2010). Quantifying ion-induced defects and Raman relaxation length in graphene. Carbon 48, 1592-1597. DOI: 10.1016/j.carbon.2009.12.057. 